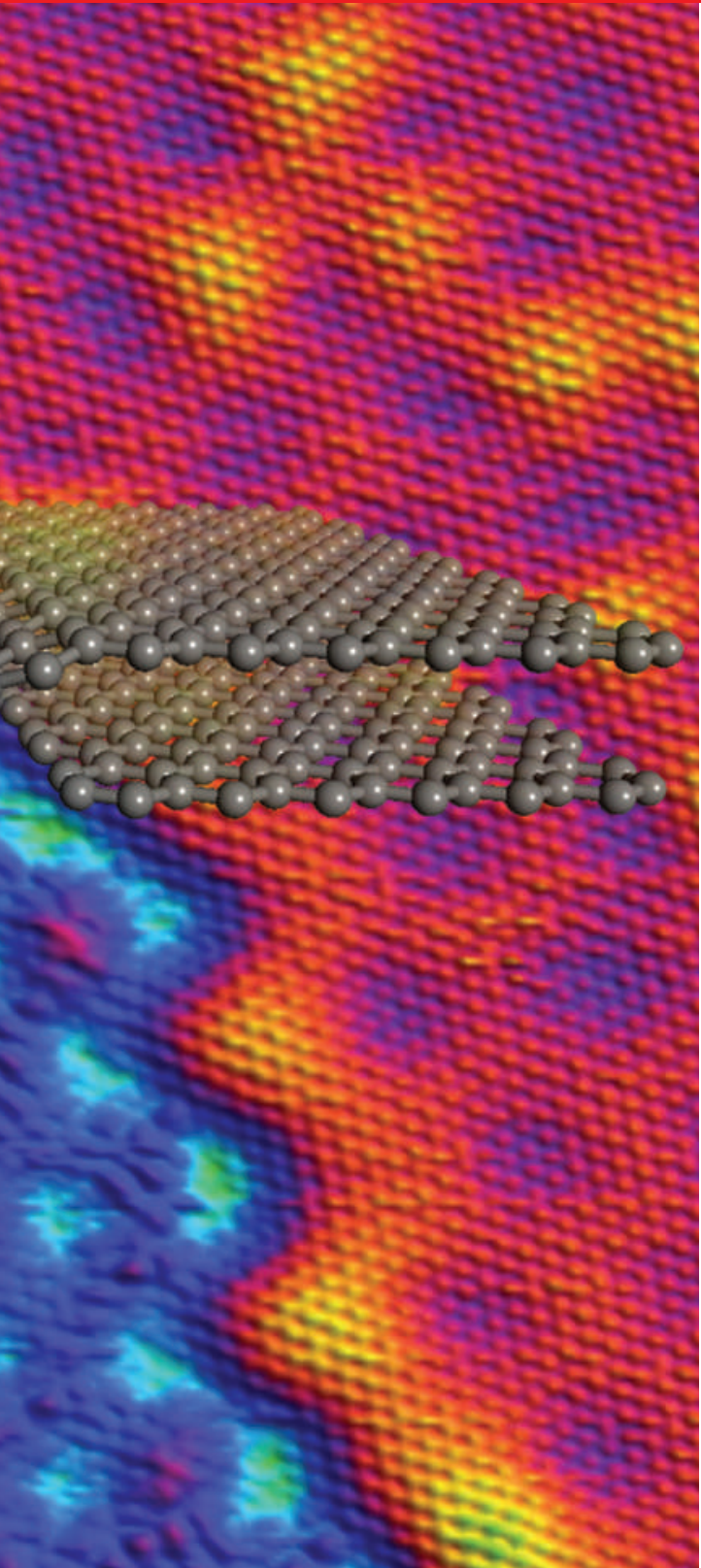

ribbons, allowing them to carry charge more easily. Even then, the scattering of electrons from the ribbon's ragged edges greatly reduces its performance. Based on these kinds of findings, Shepard believes that making these devices work will be extremely difficult. "Nothing's going to supplant silicon, not in my lifetime," he says.

Ultimately, it may be too early to tell just what graphene will - or won't - be able to do. As groups presented models and raw data from their early graphene gadgets, it became clear that many are still grappling with the latest addition to the pantheon of carbon materials. At the end of one talk, Andrea Carlo Ferrari of the University of Cambridge, UK, flashed a few slides onto the screen. Apparently, oxidizing graphene causes it to glow under infrared laser light, Ferrari told the crowd. The data are fresh, and the implications still unclear. "Will this lead somewhere?" Ferrari said afterwards with a shrug, "We don't know."

Geoff Brumfiel

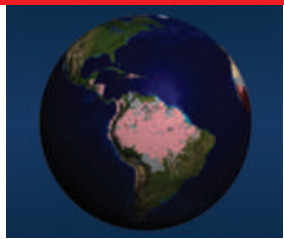

MAPPING MALARIA

Most detailed atlas of disease risk unveiled. www.nature.com/news

\title{
UK funding ban sparks protests
}

British scientists are campaigning against a plan to bar hundreds of unsuccessful grant applicants from making funding bids in the following year.

The rule, announced by the government's Engineering and Physical Sciences Research Council (EPSRC) on 12 March, aims to reduce the pressure on an overloaded system that currently peer reviews all grant applications.

But by 24 March, more than 1,200 protesters had signed an online petition (http://tinyurl.com/cvyexx) demanding that the policy be repealed. "The feeling in the community is that it is draconian and deeply unfair," says Philip Moriarty, a physicist at the University of Nottingham, UK. He and other scientists contacted by Nature say they will refuse to review their colleagues' work under such a system.

Science-funding experts think that the strategy is unique among UK, US and European funding bodies. "We could not do it in the United States. It would be very contentious," says Antonio Scarpa, director of the Center for Scientific Review at the National Institutes of Health in Bethesda, Maryland. Frank Wissing, life-sciences programme director at Germany's science funding agency, the DFG, adds that its committees have never discussed a ban on unsuccessful applicants.

The EPSRC says that scientists will not be allowed to apply for research funding for 12 months if, in the past 2 years, they have had three or more proposals ranked in the bottom half of a funding prioritization list, and also have less than $25 \%$ of all their proposals funded in that time.

The funding council says it expects 200-250 researchers will be excluded, accounting for $5 \%$ of applicants but $10 \%$ of the total number of applications submitted to the council. Those researchers are "producing a disproportionate load on the peer-review system", says Bill Wakeham, vice-chancellor at the University of Southampton, UK, and a member of the EPSRC council. Excluded scientists will have to undergo a mentoring programme to help improve their success rates before being allowed to submit grants again.

The exclusions will begin from 1 June, and the EPSRC will be contacting the first wave of scientists affected in April, says David Delpy, EPSRC chief executive. "We are a little uncomfortable with something that is applied retrospectively," he says. "But we can't wait another two years to implement it, with success rates falling as they are." Although that rate has hovered around $30 \%$ since 2004, it has dropped to just $24 \%$ in the past year.

Low success rates make applicants more cautious about spending time preparing ambitious proposals, says Delpy, and a flood of safer proposals could crowd out higherrisk but potentially ground-breaking ideas.

Chemists are most likely to be affected by the policy, says David Reid, head of marketing and communications for the EPSRC, because they tend to submit larger numbers of smaller, short-term proposals compared with other subject areas. Some funding areas with a focus on chemistry have seen success rates fall as low as $15 \%$.

"It is the chemists who are mostly complaining, and it is the chemists who produce most of the applications that fail," says Wakeham.

Tom Welton, head of chemistry at Imperial College London, echoed the feeling of many chemists contacted by Nature, calling the move a "kneejerk bureaucratic response". "We are appalled by the lack of consultation," adds Joe Sweeney, an organic chemist at the University of Reading, UK.

Reid concedes that the EPSRC did not consult widely on the specifics ut he argues that a 2007 consultation by Research Councils UK, an umbrella group for the country's research funding councils, had found that some academics supported the idea of targeted disincentives to improve success rates.

Delpy says that other options considered by the council, but rejected, included charging for submissions; applying institutional quotas; or penalizing universities by making doctoral training grants proportional to their success rates.

Along with the exclusion policy, which will be reviewed in a year's time, the EPSRC will also refuse uninvited resubmissions of failed proposals, bringing it in line with other UK research councils.

Richard Van Noorden

See Editorial, page 385 . 